\title{
DIABETES MELLITUS SOB A ÓTICA DO ADOLESCENTE
}

Larissa Evangelista Ferreira ${ }^{1}$, Elisangela Argenta Zanatta ${ }^{2}$, Maria Luiza Bevilaqua Brum ${ }^{3}$, Simone Cristina Nothaft ${ }^{4}$, Maria da Graça Corso Motta ${ }^{5}$

RESUMO: Pesquisa qualitativa realizada em $2011 \mathrm{com}$ oito adolescentes portadores de diabetes mellitus tipo 1 com objetivo de conhecer percepções e identificar limitações que esses vivenciam em face à doença no âmbito familiar, social e alimentar. Para a coleta das informações utilizou-se Dinâmicas de Criatividade e Sensibilidade preconizadas pelo Método Criativo Sensível. A interpretação das informações seguiu a análise temática de conteúdo, surgindo duas categorias: $O$ diabetes na vida do adolescente e Limitações impostas pela doença. Os resultados apontam sentimentos diversos, como esperança, alegria e tristeza e dificuldades, como cobranças feitas por profissionais de saúde e pais, horários rígidos para medicação e convivência com crises de hipoglicemia. As limitações relacionam-se às dificuldades para ser aceito e conviver com amigos e às restrições alimentares. A pesquisa trouxe elementos importantes que reforçam os observados em outros estudos, servindo de subsídios para a elaboração de cuidados de enfermagem ao adolescente diabético.

DESCRITORES: Adolescente; Diabetes mellitus; Enfermagem.

\section{DIABETES MELLITUS FROM THE POINT OF VIEW OF ADOLESCENTS}

ABSTRACT: This qualitative research, undertaken in 2011 with eight adolescents with Type 1 diabetes mellitus aimed to investigate limitations which these experience, faced with the illness in the family, social and eating ambits. The Dynamic of Creativity and Sensitivity called for by the Creative and Sensitive Method was used for data collection. The interpretation of the information followed thematic content analysis, giving rise to two categories: Diabetes in the life of the adolescent and Limitations imposed by the illness. The results indicate a range of feelings, such as hope, happiness and sadness, and difficulties, such as the requests made by health professionals and parents, strict schedules for medication, and living with hypoglycemic crises. The limitations relate to the difficulties in being accepted and co-existing with friends, and restrictions on diet. The research raised important elements which support those observed in other studies, providing support for the elaboration of nursing care for the adolescent with diabetes.

DESCRIPTORS: Adolescent; Diabetes mellitus; Nursing.

\section{DIABETES MELLITUS BAJO LA ÓPTICA DEL ADOLESCENTE}

RESUMEN: Investigación cualitativa realizada en 2011 con ocho adolescentes portadores de diabetes mellitus tipo 1 con objetivo de conocer percepciones e identificar limitaciones que eses vivieron delante de la enfermedad en el ámbito familiar, social y alimentar. Para recoger las informaciones, fueron utilizadas Dinámicas de Creatividad y Sensibilidad preconizadas por el Método Creativo Sensible. La interpretación de las informaciones fue hecha de acuerdo al análisis temático de contenido, resultando en dos categorías: El diabetes en la vida del adolescente y Limitaciones impuestas por la enfermedad. Los resultados apuntan sentimientos diversos, como esperanza, alegría y tristeza y dificultades, como cobros hechos por profesionales de salud y padres, horarios rigurosos para medicación y convivencia con crisis de hipoglucemia. Las limitaciones se refieren a las dificultades para ser acepto y convivir con amigos y a las restricciones alimentares. La investigación ha traído elementos importantes que resaltan los observados en otros estudios, sirviendo de subsidio para la elaboración de cuidados de enfermería al adolescente diabético. DESCRIPTORES: Adolescente; Diabetes mellitus; Enfermería.

\footnotetext{
${ }^{1}$ Enfermeira Assistencial do Centro Hospitalar Unimed de Joinville - SC.

${ }^{2}$ Enfermeira. Doutoranda em Enfermagem. Professora do Departamento de Enfermagem da Universidade do Estado de Santa Catarina UDESC. Membro do Grupo de Pesquisa CEVIDA da Universidade Federal do Rio Grande do Sul e do Grupo de Pesquisa Enfermagem, cuidado humano e processo saúde-adoecimento-UDESC.

${ }^{3}$ Enfermeira. Mestre em Enfermagem. Professora do do Departamento de Enfermagem da UDESC. Membro do Grupo de Pesquisa Enfermagem, cuidado humano e processo saúde-adoecimento.

${ }^{4}$ Enfermeira. Especialista em Educação Profissional, Docência e Gestão do Ensino Superior. Professora do Departamento de Enfermagem da UDESC.

${ }^{5}$ Enfermeira. Doutora em Enfermagem. Professora do Programa de Pós-Graduação em Enfermagem da Universidade Federal do Rio Grande do Sul. Líder do Grupo de pesquisa CEVIDA.
}

Autor correspondente:

Recebido: $16 / 05 / 2012$

Simone Cristine dos Santos Nothaft

Aprovado: 30/01/2013

Universidade do Estado de Santa Catarina

R. Pedro J. Werlang, 135 - 89885-000 - São Carlos-SC-Brasil

E-mail: nothaft@hotmail.com 


\section{INTRODUÇÃO}

A adolescência é uma fase de intensos descobrimentos e vivência de novas experiências. Sendo assim, cuidar desse segmento da população é um desafio, pois constitui uma etapa do curso da vida marcada por mudanças intensas e multidimensionais que envolvem o plano biológico, psicológico e social. No plano biológico as mudanças são mais visíveis, uma vez que englobam modificações no corpo do adolescente, provocadas pela ação hormonal que leva a alterações na sua maneira de se portar e se expressar ${ }^{(1)}$.

Para muitos adolescentes essa fase pode se configurar em uma etapa difícil e conflituosa, principalmente pelas particularidades que envolvem a afirmação consigo mesmo, com a família, com o grupo de amigos e com a sociedade. Entretanto, pode ser ainda mais complicada de ser vivenciada quando o adolescente precisa conviver com uma doença crônica, nesse caso, especificamente, com o diabetes mellitus tipo 1 (DM1).

$\mathrm{O}$ diagnóstico de diabetes é quase sempre motivo de ansiedade para o adolescente por se tratar de uma doença crônica, de etiologia incerta e que pode ocasionar complicações para sua rotina. Especialmente, porque este se encontra numa fase de consolidação da personalidade e busca pela aceitação de um grupo sociall ${ }^{(2)}$. Comumente os adolescentes têm mais dificuldades para aceitar a doença quando comparados à crianças, pois, enquanto estas ainda dependem dos cuidados dos pais ou responsáveis, os adolescentes são evocados a responsabilizar-se pela própria saúde. Observa-se, porém, que sua imaturidade pode dificultar o autocuidado, especialmente no que diz respeito à administração de medicamentos e o seguimento de $\operatorname{dieta}^{(3)}$.

Nesse contexto, torna-se difícil e estressante para os adolescentes seguirem rigorosamente o tratamento para o controle metabólico do DM1. Estes estão vivenciando uma etapa da vida em que gostam de sentirem-se iguais aos seus pares e buscam constantemente viver dentro dos padrões normais de saúde expressos pela sociedade ${ }^{(4)}$.

Conviver com DM1 faz o adolescente experienciar sentimentos de perda, ansiedade, medo, revolta, impotência e desconforto. Entretanto, são conscientes de que para sobreviver precisam rever seu padrão de vida e, para isso, buscam a auto superação, aceitação e resignação. Porém, tais vivências mostram-se diferentes conforme a maturidade de cada adolescente, a fase da doença e o contexto de vida ${ }^{(5)}$. Em meio a essas dificuldades, a tomada de consciência para assumir o problema vai aos poucos se conformando e as responsabilidades, anteriormente atribuídas à mãe ou à equipe de saúde, são progressivamente assumidas pelo adolescente que adapta-se ao novo estilo de vida, com suas restrições e ajustes ${ }^{(5)}$.

A partir dessas considerações, entende-se ser imprescindível conhecer a relação do adolescente com o DM1 para elaborar um plano de cuidados de enfermagem que possa auxiliar o adolescente a enfrentar, com mais facilidade, os problemas que se apresentam a partir do diagnóstico e no controle diário da doença. Sendo assim, julgou-se oportuno realizar uma pesquisa guiada pelos seguintes objetivos: conhecer percepções dos adolescentes sobre seu viver com diabetes mellitus tipo 1 e identificar limitações vivenciadas em face à doença no âmbito familiar, social e alimentar.

\section{MÉTODO}

Pesquisa qualitativa realizada em 2011 com oito adolescentes que convivem com DM1, cadastrados no Centro de Referência de Especialidades Municipais de um município do Oeste de Santa Catarina. Como critérios de inclusão foram estabelecidos: ter idade ente 10 e 19 anos, de ambos os sexos, e ter o diagnóstico de DM1 há pelo menos seis meses.

Para a coleta das informações utilizou-se o Método Criativo Sensível (MCS) $)^{(6)}$, que tem nas Dinâmicas de Criatividade e Sensibilidade (DCS) seu dispositivo central de produção de dados para a pesquisa científica, pois, além de combinarem as discussões de grupo com a produção artística, nelas ocorrem a observação participante e as entrevistas coletivas.

O MCS é composto por cinco momentos: $1^{\circ}$ ) preparação do ambiente e acolhimento do grupo; $2^{\circ}$ ) apresentação dos participantes do grupo; $3^{\circ}$ ) explicação da dinâmica e atividade individual ou coletiva; $4^{\circ}$ ) apresentação das produções e análise coletiva; $5^{\circ}$ ) validação dos dados. Nesta pesquisa não foi utilizada a etapa validação dos dados.

A coleta das informações efetivou-se em um encontro realizado em sala reservada, exclusivamente, para esta atividade, com duração de duas horas. Os adolescentes foram recepcionados e convidados a acomodarem-se formando um círculo. No meio desse, foram disponibilizados materiais para a realização da DCS, conduzida a partir da questão: "como é para você conviver com o diabetes?" As respostas para esse questionamento foram expressas por meio de desenhos, construídos por cada adolescente. $\mathrm{Na}$ etapa seguinte ocorreu a socialização dos desenhos 
e a explicação desses, por cada adolescente, constituíram o material para interpretação.

Para a interpretação das informações utilizou-se a análise temática de conteúdo ${ }^{(7)}$, composta por três etapas. A pré- análise constitui-se de leitura compreensiva do conjunto de material produzido, objetivando ter uma visão de todo. A exploração do material deu-se por meio da distribuição de trechos, frases ou fragmentos das falas dos adolescentes e reagrupação temas encontrados. Na sequência ocorreu a redação de cada tema, intercalando com conclusões dos pesquisadores à luz de estudos acerca da temática. Na última etapa, deu-se o tratamento dos resultados/ interferência/interpretação: elaboração de síntese interpretativa com diálogo entre os temas, objetivos, questões e pressupostos da pesquisa.

A pesquisa foi aprovada pelo Comitê de Ética em Pesquisa da Universidade do Estado de Santa Catarina - UDESC, parecer n. 125/2011. Foi desenvolvida, após assinatura do TCLE pelos pais de cada adolescente e da assinatura do Termo de Assentimento pelo adolescente, respeitando os aspectos éticos e legais, respaldados na Resolução n. 196/96 sobre a pesquisa envolvendo Seres Humanos $^{(8)}$.

\section{RESULTADOS}

O método adotado possibilitou construir duas categorias de análise: O diabetes na vida do adolescente; Limitações impostas pela doença.

\section{Diabetes na vida do adolescente}

Nessa categoria apresenta-se como o adolescente percebe o diabetes na sua vida, sentimentos e dificuldades encontradas para conviver com a doença no seu cotidiano. Sentimentos de esperança pela cura do DM1 pode ser percebido na fala a seguir:

Minha esperança é ser normal, sem diabetes. (Adolescente 2)

Sentimentos de alegria e tristeza se intercalam no cotidiano do adolescente, influenciados pelas alterações dos níveis glicêmicos, ilustrados no depoimento:

Ah, prá mim conviver com o diabetes é assim, tem dias que en estou feliz, tem dias que estou triste. Porque quando estou triste é porque minha glicose está alta, quase todos os dias [risos]. (Adolescente 7)
Em meio aos sentimentos de esperança, alegria e tristeza pode-se perceber a aceitação e a negação do diabetes; a aceitação relaciona-se ao período de tempo decorrido após o diagnóstico, como externado:

É que já faz 8 anos que tenho diabetes, vontade [de doces] já não dá mais. (Adolescente 5)

Os adolescentes destacam como dificuldades para conviver com o DM1 incorporar à sua rotina exigências do tratamento, rigor nos horários das medicações, para manter os níveis glicêmicos adequados, realização de dosagens glicêmicas várias vezes ao dia e convivência com as cobranças dos profissionais de saúde e dos pais. Os depoimentos a seguir ilustram as dificuldades:

A maior dificuldade é os horários, tem que ter hora prá tudo. (Adolescente 6)

Eu odeio fazer exames. Você tem que ir lá, fica esperando e ficar furando o dedo, fica tirando sangue. (Adolescente 2)

Também tem a doutora, ai se eu venho aqui e minha glicose tá alta, meu Deus, ela já vem falá um monte de coisa. (Adolescente 7)

Meus pais não deixam entrar nada o que é doce dentro de casa. Mas aí, quando eles vão viajar eu sempre compro alguma coisa [risos]. Ela [a mãe] não me deixa nem eu dormir na casa dos meus amigos prá eles não me oferecerem [doces]. (Adolescente 2)

A doença produz ainda algumas lembranças marcantes, geralmente relacionadas a momentos que os adolescentes tiveram sintomas de mal estar associado aos níveis glicêmicos descompensados. Esses relataram as crises de hipoglicemia como uma das maiores dificuldades do tratamento:

Sempre tenho que ter alguma coisa junto prá caso a glicose baixar [...]. Já aconteceu de eu estar andando na rua e minha glicose baixar, eu começar a passar mal [...]. (Adolescente 6)

Uma vez também minha glicose baixou quando eu estava dormindo, dai não sei o que deu que теи pai levantou. Tava tão baixa que o aparelho nem marcou e eu nem respondia mais. (Adolescente 5) 
Apesar das dificuldades relatadas, alguns adolescentes declaram utilizar a doença como uma forma de obter proveito em determinadas situações:

Ah, às vezes quando quero faltar aula, peço prá professora prá sair porque minha glicose está baixa. (Adolescente 2)

Às vezes eu falava prá minha mãe que minha glicose estava baixa, ai ela falava: 'vai lá comer um docinho então'. (Adolescente 8)

O diabetes influencia o cotidiano do adolescente, acarretando alguns incômodos. Incorporar as exigências do tratamento o leva a reagir de forma diferente. Alguns aceitam a doença e assumem o autocuidado, outros se tornam rebeldes e aproveitam-se da condição para obter benefícios, outros convivem com sentimentos que oscilam da tristeza à esperança pela cura do diabetes.

\section{Limitações que a doença impõe}

Nessa categoria aparecem duas questões: dificuldade de conviver com o grupo de amigos e restrições alimentares impostas pelo DM1.

As dificuldades foram manifestadas na produção artística de um adolescente (Figura 1). Algumas situações, típicas do viver do adolescente, apresentam-se como armadilhas que requerem maturidade para a tomada de decisões a fim de não desestabilizar sua condição de saúde.

A restrição alimentar é ilustrada na figura 2 e nos depoimentos:

Meu desenho é chocolate, porque eu gostava muito e agora não posso mais comer. (Adolescente 4)

Minha alimentação é normal, só mais controlada [...]. Às vezes sinto falta de algumas coisas[...]. O que mais sinto falta é chocolate. (Adolescente 3 )
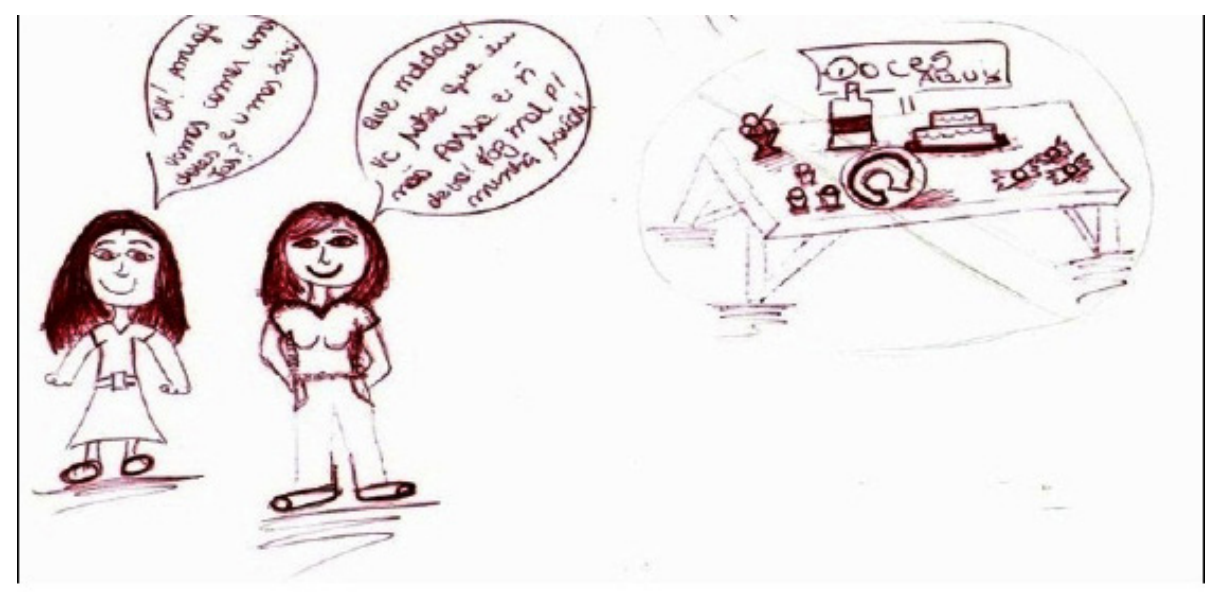

Figura 1 - Produção artística do Adolescente 8 referente ao conviver com as restrições impostas pela doença em um grupo de amigos. Chapecó, 2011

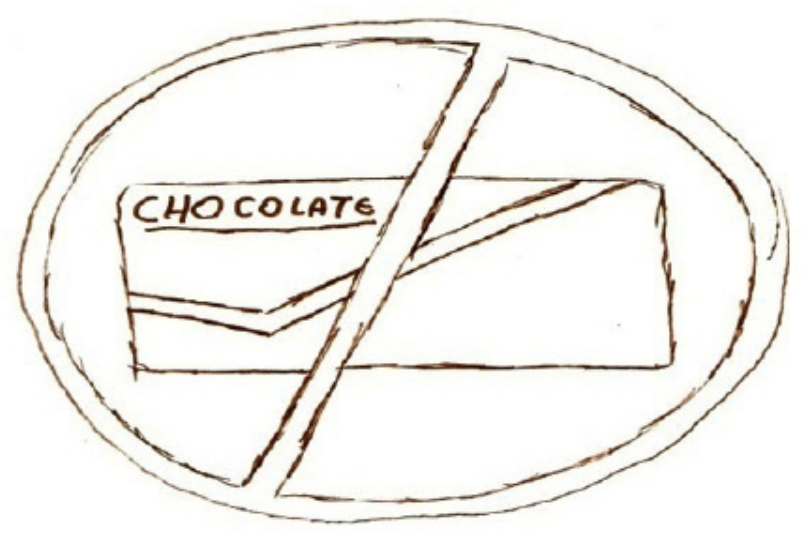

Figura 2 - Desenho do Adolescente 4 referente as restrições alimentares impostas para o controle da doença. Chapecó, 2011 


\section{DISCUSSÃO}

Sonho, esperança, alegria e tristeza foram sentimentos manifestados pelos adolescentes, revelando que o diabetes tem um significado importante e, talvez decisivo para suas vidas quando fazem planos para o futuro, vislumbrando a cura da doença. Entendem que a cura é uma condição para sentirem-se normais, tendo em vista que consideram-se diferentes dos demais por conviverem com a doença. Entretanto, a esperança da cura os move para suportar as inúmeras restrições que lhes são impostas no dia-a-dia.

Em um estudo sobre as perspectivas futuras e incertas relacionadas ao tratamento do DM1, realizado com adolescentes, o desejo da cura da doença também foi manifesto. Os adolescentes demonstraram acreditar que em um futuro próximo seriam curados, porém sem uma certeza concreta, baseada, mormente na sua fé em um Ser superior, situação que lhes favorece maior adesão ao tratamento. A esperança de cura ajudou-os a assumirem, com mais responsabilidade, os cuidados com a doença e possibilitou diminuir as crises de hipo ou hiperglicêmia e, por conseguinte, as complicações decorrentes do DM não controlado( ${ }^{(9)}$.

Os adolescentes deste estudo revelam que a aceitação da doença possui uma relação direta com o tempo decorrido do diagnóstico, pois com o passar do tempo aprendem a conviver com a doença e suas privações, conseguindo levar uma mais vida tranquila e mais próxima da normalidade. Mesmo sabendo conviver e adaptar-se às limitações impostas pela doença, não significa que o adolescente aceite-a. O tempo de convivência apenas deixa-o mais habituado e maduro para vivenciar determinadas situações. Mesmo assim, surgem problemas, especialmente quanto à rigidez de horários para cumprir com o tratamento, cobranças dos profissionais de saúde e familiares, e ainda ter que estar sempre atento para evitar as crises de hipoglicemia e suas consequências.

O diagnóstico traz consigo, além da notícia devastadora de que passam à condição de diabéticos, uma grande quantidade de informações que vão normatizar suas vidas, restringindo-os à liberdade de serem como antes ${ }^{(10)}$. Essa nova condição provoca instabilidade na rotina do adolescente que, a partir desse momento, precisa organizar seu dia pensando nas atividades que obrigatoriamente terá que cumprir e relacionadas, principalmente, à alimentação, à prática de exercícios, e mesmo às atividades rotineiras ${ }^{(2)}$.

Logo após a descoberta da doença, o adolescente refere não ter a dimensão exata do que se constitui ser diabético e quais serão suas consequências. No entanto, na medida em que o tempo passa, ele reconhece que para ficar bem necessita seguir o tratamento recomendado, conscientizando-se sobre a sua condição. Esse é um momento muito importante, porque ele passa a perceber o diabetes como algo não desejado, porém que não é incompatível com seu estilo de vida, conseguindo manter-se controlado ${ }^{(11)}$.

É comum os adolescentes reclamarem, inclusive, de suas atividades de rotina, como horários para estudo e outros compromissos. Em relação ao diabetes, é ainda mais complicado conseguir administrar todas as exigências do tratamento, que compromete sua liberdade pela dependência em cumprir as normas e restrições necessárias para manter o controle da doença.

Além disso, o adolescente precisa conviver com as cobranças realizadas pelos profissionais de saúde e família, quanto aos cuidados e restrições que precisa incorporar à sua vida. Os pais, por sua vez, podem ter dificuldades nesse novo papel: percebem-se como fiscalizadores, privando os filhos de terem uma vida normal, pois temem pela sua segurança e bem estar ${ }^{(12)}$. Por outro lado, a independência e autonomia do adolescente geram sofrimento nos familiares que temem pela não observância do tratamento. O relacionamento estabelecido entre familiares e adolescentes com DM1 é de fundamental importância, visto ser este marcado por momentos alternados de cuidado, carinho, segurança e também crises, conflitos e desentendimentos ${ }^{(13)}$.

Em meio a essas questões que envolvem pais e adolescentes é pertinente destacar que alguns adolescentes aprendem que podem manipular fatos, utilizando-se da doença para obter vantagens e fugir de situações que não lhes agradam. Essa atitude pode ser interpretada como um comportamento de rebeldia pois, por não compreenderem os motivos e as razões das regras que lhes são colocadas, encontram meios alternativos de fugir dessas, utilizando-se de mentiras e omissões.

Em relação à convivência com os amigos, destacam a importância de serem aceitos e incorporados ao grupo. Entretanto, salientam que esse pode influenciar, de maneira positiva ou negativa, no controle doença. Para isso, precisam ter maturidade para assumir as consequências de suas atitudes e decisões. O grupo de amigos é um espaço onde os adolescentes compartilham segredos e experiências. Geralmente a cobrança, em relação aos cuidados com o diabetes não está presente neste espaço e não haverá reprovação de suas atitudes se ele fizer algo que não está de acordo com as normas. Sendo assim, é comum o adolescente quebrar algumas regras quando está com os amigos, uma vez que ter atitudes semelhantes da maioria do grupo é uma forma de incorporar-se a ele.

O suporte dos amigos é importante para ajudar o adolescente a enfrentar a sua doença e conviver com ela. 
A presença dos amigos proporciona o elo que the assegura os vínculos com o seu mundo, dando-lhe uma sensação de ainda pertencer a esse mundo ${ }^{(10)}$.

As restrições alimentares, impostas pelo DM1, foram apontadas como uma das grandes limitações que a doença acarreta, principalmente no que diz respeito a ter que se privar de alimentos que mais the agradam. A predileção pelos alimentos restritos ocorre porque aquilo que é proibido é o que chama mais atenção do adolescente. Além disso, nessa fase, viver sob risco e quebrar regras é uma forma de amadurecimento para eles; então, manter-se numa dieta saudável e equilibrada é um problema dentro do mundo do adolescente que convive com o DM1 ${ }^{(14)}$.

Sendo assim, a abordagem com o adolescente que convive com o DM1, em relação à alimentação, deve priorizar a educação sobre a importância de manter uma alimentação saudável para suprir a demanda energética. Além disso, é importante salientar que os doces e demais alimentos extremamente calóricos não são restrito somente a ele, mas devem ser evitado por todos aqueles que desejam ter uma alimentação saudável.

O apoio dos profissionais de saúde e enfermagem é importante para que se estabeleçam ajustes nas relações familiares, de amigos e na individualidade do próprio adolescente. Este estando amparado e informado se instrumentaliza para realizar mudança de hábitos necessários para superar as crises e as dificuldades, e com isso conviver melhor com o DM1.

\section{CONSIDERAÇÕES FINAIS}

Viver a etapa da adolescência com diabetes significa ter algumas restrições que exigem hábitos mais cuidadosos com a saúde. Entretanto, os adolescentes dessa pesquisa mostraram que não deixam de viver nenhum aspecto desta etapa do desenvolvimento humano por serem portadores de uma doença crônica, apenas se restringem a algumas limitações.

Apesar de apontarem algumas dificuldades, especialmente no convívio com amigos e na incorporação das exigências do tratamento na sua rotina, declaram que essas podem ser ultrapassadas quando possuem o apoio dos familiares e de amigos dispostos a ajudar. Principalmente, quando o adolescente tem consciência sobre seu problema e está disposto a enfrentá-lo.

Alguns adolescentes deixaram transparecer comportamentos de rebeldia e sofrimento com a terapêutica, negando a doença por determinado tempo, até que aceitem-na como condição de vida. Esse período é crucial para alguns determinantes na vida do adoles- cente. Nesse cenário é importante que os profissionais de saúde, sobretudo, o enfermeiro, estejam atentos para dar suporte ao adolescente e sua família.

Essa intervenção profissional precisa ser dialógica, no sentido de acolher e entender o que se passa com cada adolescente, visando auxiliá-lo no autocuidado. Também ser um mediador na transição da fase de negação para aceitação, respeitando o tempo de cada um para aceitar o diagnóstico e aceitar-se como um ser que deverá conviver com uma doença crônica, para então planejar e implementar medidas de cuidado individuais e coletivas, de acordo com as suas necessidades e particularidades.

Compreender o DM1 no contexto da adolescência se constitui em um desafio, porém permite ao enfermeiro aproximar-se e conhecer as características que permeiam seu universo, visando com isso ser um articulador do cuidado nas dimensões individual, social, cultural e das políticas públicas de saúde.

Como limitação do estudo destaca-se a dificuldade de sensibilizar o adolescente para discussões e reflexões sobre o conviver com o DM1. Essa situação pode inviabilizar ações que instrumentalizem o adolescente para o autocuidado e dificultar ao a identificação de outros elementos intrínsecos à doença que possam causar impactos na sua vida. Recomenda-se, portanto, que esse tema seja ampliado em outras investigações.

\section{REFERÊNCIAS}

1. Marques JF, Silva KM, Moreira KAP, Queiroz MVO. Saúde e cuidado na percepção de estudantes adolescentes: contribuições para a prática de enfermagem. Cogitare enferm. [Internet]. 2012;17(1) [acesso em 13 abr 2012]. Disponível: http://ojs.c3sl.ufpr. br/ojs2/index.php/cogitare/article/viewFile/26372/17565

2. Fialho FA, Dias IMAV, Nascimento L, Motta PN, Pereira SG. Crianças e adolescentes com diabetes mellitus: cuidados/implicações para a enfermagem. Rev. baiana enferm. [Internet] 2011;25(2) [acesso em 02 jan 2013]. Disponível: http://www.portalseer.ufba. br/index.php/enfermagem/article/view/4820/4467

3. Minanni CA, Ferreira AB, Sant'Anna MJC, Coates V. Abordagem integral do adolescente com Diabetes. Adolesc. Saude. [Internet] 2010;7(1) [acesso em 02 jan 2013]. Disponível: http://www.adolescenciaesaude.com/ detalhe_artigo.asp?id=181

4. Fragoso LVC, Araújo MFM, Lima AKG, Freitas RWJF, Damasceno MMC. Vivências cotidianas de 
adolescentes com diabetes mellitus tipo 1. Texto Contexto Enferm. [Internet] 2010;19(3) [acesso em 02 jan 2013]. Disponível: http://www.scielo.br/pdf/tce/ v19n3/a05v19n3.pdf

5. Almino MAFB, Queiroz MVO, Jorge MSB. Diabetes mellitus na adolescência: experiências e sentimentos dos adolescentes e das mães com a doença. Rev Esc Enferm USP. [Internet] 2009;43(4) [acesso em 02 jan 2013]. Disponível: http://dx.doi.org/10.1590/S008062342009000400004

6. Cabral IE. Uma abordagem criativo e sensível da pesquisa a família. In: Althoff CR, Elsen I, Nietschke $\mathrm{RG}$, organizadores. Pesquisando a família: olhares contemporâneos. Florianópolis: Papa Livros; 2004. p. 127-39.

7. Minayo MCS. O desafio do conhecimento: pesquisa qualitativa em saúde. São Paulo: Hucitec; 2010.

8. Ministério da Saúde(BR), Conselho Nacional de Saúde. Resolução n. 196, de 10 de outubro de 1996: Diretrizes e normas regulamentados de pesquisa envolvendo seres humanos. Brasília (DF); 1996.

9. Barreto MS, Silva AM, Nortean ECM, Marcon SS. Conviver com diabetes mellitus sob a ótica de adolescentes e jovens e suas mães. Rev. pesq.: cuidado é fundamental. [Internet] 2012;4(4) [acesso em 02 jan 2013]. Disponível: http://www.seer.unirio.br/index.php/ cuidadofundamental/article/view/1892

10. Ghelman LG. O Cotidiano do adolescente portador de diabetes: um estudo na perspectiva fenomenológica [tese]. Rio de Janeiro (RJ): Universidade Federal do Rio de Janeiro; 2009.

11. Damião EBC, Dias VC, Fabri LRO. O adolescente e o diabetes: uma experiência de vida. Acta Paul Enferm. [Internet] 2010;23(1) [acesso em 02 jan 2013]. Disponível: http://dx.doi.org/10.1590/5010321002010000100007

12. Brito TB, Sadala MLA. Diabetes mellitus juvenil: a experiência de familiares de adolescentes e préadolescentes. Ciênc. saúde colet. [Internet]. 2009;14(3) [acesso em 27 out 2011]. Disponível: http://www.scielo. br/pdf/csc/v14n3/31.pdf

13. Leal DT. Diabetes na infância e adolescência: o enfrentamento da doença no cotidiano da família. HU Revista [Internet]. 2009;35(4) [acesso em 27 out 2011]. Disponível: http://www.seer.ufjf.br/index.php/ hurevista/article/viewFile/831/285
14. Fragoso LVC, Araújo MFM, Lima AKG, Freitas RW JF, Damasceno MMC. Vivências cotidianas de adolescentes com diabetes mellitus tipo 1. Texto Contexto-Enferm. [Internet]. 201019(3) [acesso em 202 jul 2011]. Disponível: http://www.scielo.br/pdf/tce/ v19n3/a05v19n3.pdf 